\title{
Inspecting the Results of Renewable Energy Source of Solar Botanic Trees Using Nano Piezo Electric Elements
}

\author{
K.M. Meghana, D.J. Sharavathi, M. Kushma and G. Manjula
}

\begin{abstract}
The world is suffering under the severe shortage of reliable and efficient energy resources. The environmental friendly energy resources used to generate electricity so far. Thus, as a result we are seeing greenhouse effect and global warming and there is an immediate call to change over to an environmental-friendly energy resource i.e., 'the Renewable Sources. It eliminates the problems faced by a ancient solar panels. In case of Solar Botanic Trees, if the wind force is high, then the more Nano-leaves are moved. Nano piezo-electric elements associated in the petiole twigs and branchesare the tiny Nano piezo-electric elements that will generate Pico watts of energy as these thousands of Nano leaves flap back and forth due to wind. The stronger the wind force, the higher the "overlap" frequency, and therefore the larger the watts of energy generated in the petiole, twigs and branches. The mechanical vibrations in these mini generators produce electricity from movement of botanic tree leaves or kinetic energy caused by wind or falling raindrops.
\end{abstract}

Keywords--- Fossil fuels, Nano leaves, Piezoelectric, Reneuable source, Generators, Energy, Solar Botanic Trees.

\section{INTRODUCTION}

$\mathrm{N}$ ATURAL resources are fast depleting. With a drastic increase in the price of fossil fuels, we should need alternative resources to go on with our daily activities. While we scratch our heads thinking of various ways to reduce our carbon foot print, solar botanic trees has given a unique solution called Energy Harvesting. Trees that will provide renewal electricity through solar and wind energy using botanical trees. Several Renewable Sources are considered as an alternative for the present energy unavailability. However, they have some limited applicability. Energies like Hydro energy, Wind energy, Solar energy are all renewable energy resources applications. But, several drawbacks are posed by these sources like

- Costlier manufacturing.

- High installation and maintenance cost.

- Environmental dangers.

K.M. Meghana, Student, Dept of CSE, SSCE, Banglore, India. E-mail: Kmmegha123@gmail.com

D.J. Sharavathi, Student, Dept of CSE, SSCE, Banglore, India. E-mail:sharavathisajjandj@gmail.com

M. Kushma, Student, Dept of CSE, SSCE, Banglore, India. E-mail:Gmreddy0999@gmail.com

G. Manjula, Asst. professor, Dept of CSE, SSCE, Banglore, India. E-mail:Manjulag.cse@sairamce.edu.in

DOI:10.9756/BIJSESC.8234
- $\quad$ Decrease in property and land values.

- Building modulation.

There is no difference between fake tree and real one. If woodpecker makes a hole, then the material used inside the tree will get destroyed. Thus, we will present a new method of elcubarating how we can use today's technology in a more efficient and effective way without causing any environmental pollution and the concept shown in this paper will give a various design techniques in renewable energy sources.

\section{BIO-MIMICRY}

Our solution is primarily based on the principle of 'Distributed generation'. This solution is loosely based on the principle of Bio mimicry is an emerging discipline that studies nature's best ideas and then imitates these works of design and processes to solve human problems. It is the practice of developing renewable human technologies inspiered by the nature.

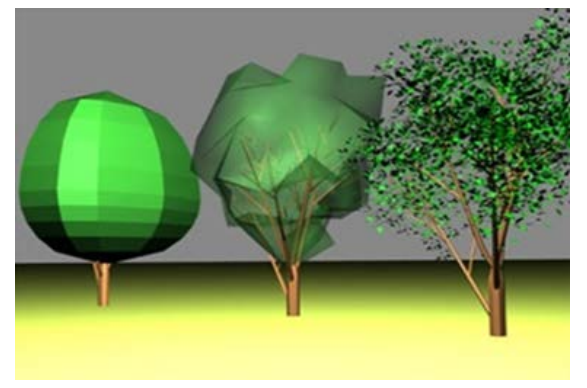

Fig. 1: Botanic Trees

We have abundant examples around us inspired by nature like Bionic Car: Daimler Chrysler has developed a new car concept from Mercedes-Benz based on the shape of an old tropical fish the Bionic Car. Using the shape of the tropical boxfish, designers introduced a modernised ideal that boasts $20 \%$ less fuel consumption and as much as an $80 \%$ of nitrogen oxide emissions are reduced. The diesel-powered compact will get about 70 miles per gallon, and can run just fine on biodiesel fuel.

\section{SOLAR BOtANIC TREES}

Solar Botanic will introduce substitute trees that will use renewable energy from the sun and wind, they are an efficient clear and environmental sound mean of collecting solar radiation and wind energy. This plan will collectively bring3 different energy generations together. They are 
- Photovoltaic (PVS) are series of cells containing a material that converts sun radiation into direct current electricity. Materials presently used for photovoltaic are amorphic silicon, polycrystalline silicon, microcrystalline silicon, cadmium telluride etc.

- Thermoelectricity refers to a group of phenomena in which a difference in temperature creates an electric potential or a electric potential creates a difference in temperature.

- Piezoelectricity is the ability of some materials to produce an electric field or electric potential in response to applied mechanical stress.

- Traps the power of the sun, conjoin all aspects of a tree such as leaf, branch and twigs and convert sun energy to electricity to power cities, auto and highways. In this bio mimicry conceptal view our trees are fitted with Nano leaves, a combination of Nano-photovoltaic, Nano-thermo and Nano-piezo generators converting light, and heat into green electricity.

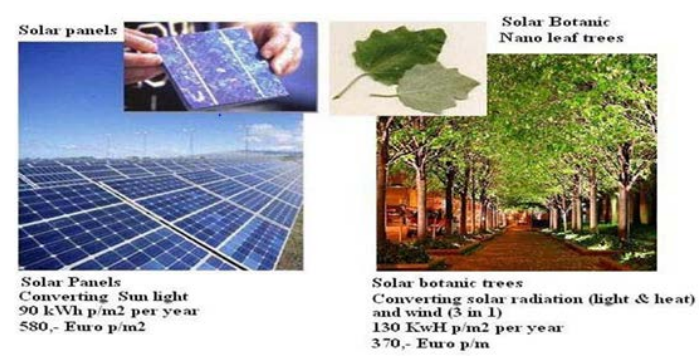

Fig. 2: Solar Panels Compared to Solar Botanic Trees

\section{NANO LEAF}

The fundamental element in this technology is Solar Botanic's artificial leaf called the 'Nano leaf'.

- Nanoleaf consists of a very thin photovoltaic film on one side, which converts the light from the sun into energy.

- The other side of the nano leaf contains thin thermo voltaic film that converts the heat from the solar energy into electricity.

- In addition to solar power, as whispering wind or falling rain disturbs the false leaves, Nano generators in their petioles. The stalks connecting them to a branch should generate small amounts of piezoelectric power. A Nano leaf is slinky like a feature weight like a natural leaf, when external forces, like the wind force, forcing the Nano leaf to move back and forth, then the mechanical stresses will appear in the petiole, twig and branches. When thousands of Nano leaves overlaps back and forth due to wind force, millions and millions of Pico watts of energy will be generated, if the wind force is high then the more energy is generated. Our Nano leaves only reflect a small part of the sunlight that strikes them, commonly the green light, and the rest of the spectrum is effectively converted into electricity.

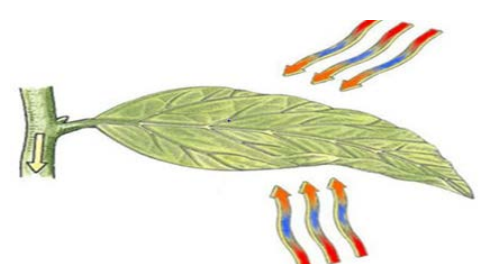

Fig. 3: Photo Voltaic Energy Conversion in Nano Leaves

With converting the visible spectrum of light, our Nano leaves also convert the invisible light like infrared light or radiation, we can't see it, but we can feel it- it is so warm so only we call it as radiation. Due to the rear combination of photovoltaic and thermo voltaic in our Nano leaves which converts this thermal radiation into electrical energy, even after the sunset. If the wind force is high then the more Nano leaves are moved. Wind force that is moving thousands of Nano leaves in a tre e covering are causing mechanical stress in the petiole, twigs and branches. Nano piezo-electric elements intergrated in the petiole twigs and branches are the mini Nano piezo-electric elements that will generate millions and millions of Pico watts of energy as these thousands of Nano leaves move back and forth due to wind. The stronger the wind, the higher the "overlap" frequency and therefore the larger the watts of energy is generated in the petiole, twigs and branches.

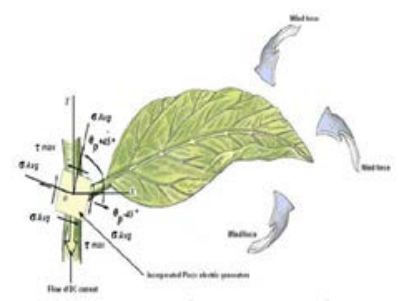

Fig. 4: Process of Green Energy Producer

With the voyage in Nano technology, the photovoltaic, thermo voltaic and piezo electric materials are becoming more adequate and are combined in one system to give our products more efficiently and we believe that soon, Solar Botanic will be a mainstream green energy producer, more reliable or cheaper and above all better looking.

\section{TYPES OF NANO LEAFS}

- Broad and wide spread Leaf trees: These variety can provide electricity that ranges between $3500 \mathrm{kWh}$ to $7000 \mathrm{kWh}$ per year. They provide shade by cooling the environment, green environ and much more. Ever green trees- this variety can provide between $2500 \mathrm{kWh}$ and $7000 \mathrm{kWh}$ per year. They can be placed as single tree or to chain garden properties.

- Shrubs, Plants, Roof, Wall and Fencing: A vast range of shrubs are required for electrical needs. Nano leaf roof matting can be installed in minutes on any roof design. For fencing Wall runners are easy.

\section{CAPACITY OF BotaniC TREES}

An regular tree with a canopy of about 6 sq. meters can create sufficient energy to provide for the needs required by an average household and a tree with a $20 \mathrm{ft}$ solar canopy could generate enough power range between 2000 and $12000 \mathrm{KWh}$ 
per year. An intermitting operation over two decades could produce $1,20,000 \mathrm{KWh}$ of energy. On a larger scale, a kilo meter of solar botanic trees would be able to produce approximately 350,000 $\mathrm{kWh}$ per year, sufficient energy to power approximately 60 average size houses. Solar Botanic solutions offer up to $50 \%$ more power than conventional solar systems.

\section{APPLICATIONS}

- It can be installed in Urban and Rural areas.

- $\quad$ Effectively used in Recreational parks, city parks

- New housing estate.

- Mountainous regions

- Coastlines

- Highways

- Airports

- $\quad$ Penthouses, balconies, verandas private gardens.

- De-forested areas where no more trees can be cultivated.

- Lands of commercial interest; Islands, surrounding nature tourist trap like resort.

- $\quad$ Ponds, lakes, seas and oceans

- Crop Protection

- Solar Botanic flowering plants to yielding colourful your electric power. Solar Botanic can be used for: Wind shield, Shade, anti-blaze, objectionable views, sound barrier, windbreak, wind blockage and much more.

\section{BENEFITS}
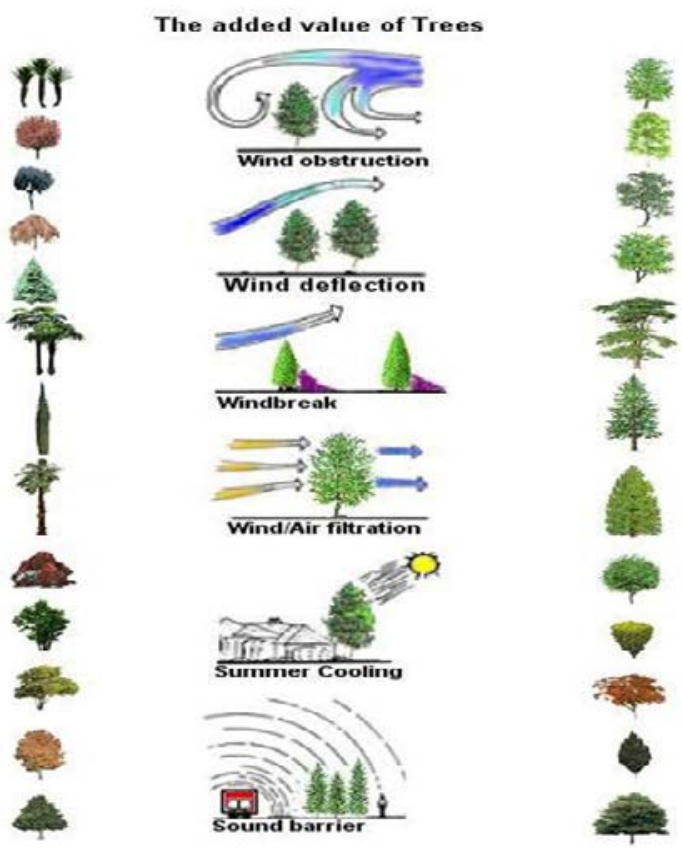

Fig. 5: Botanic Trees at Different Weather Conditions

\section{CONCLUSION}

India is the 2nd largest country of the world, the increasing demand of the energy has forced the mankind to find a way will be efficiently and abundantly available source of energy.
As the solar botanic trees is a non-conventional source, we have many benefits of producing electricity compared to the other resources. Green Energy is the need of the hour and it is our responsibility to ensure a secure a safer planet for the future generations. It is therefore fundamental responsibility of the citizens of the earth, or shall we say mankind to think smart and take the right decision. Everything starts with an individual, work together with the government and see your progeny enjoy the fruit of your action make life favorable for sustenance for mankind.

\section{ACKNOWLEDGEMENT}

The authors would like to thanks for giving an opportunity to present our paper in national conference on advances in computer science and engineering at SRI DHARMASTALA MANJUNATHESWHARA COLLEGE OF ENGINEERING AND TECHNOLOGY.

\section{REFERENCES}

[1] Z. Bilkadi, "BULLS FROM THE SEA : Ancient Oil Industries", Aramco World. Archived from the original on 2007-11-13, 1992.

[2] M.W. Ball, D. Ball and D.S. Turner, "This Fascinating Oil Business" Indianapolis: Bobbs-Merrill, ISBN 0-672-50829-X, 1965.

[3] R. Kaldany, "Global Gas Flaring Reduction: A Time for Action!(PDF)", Global Forum on Flaring \& Gas Utilization, Retrieved 2007-09.

[4] Paul Weiss, "Renewable Resources, a report to the committee on natural resources of National Academy of Science-National Research Council(1962)", Washington D.C., USA.

[5] A. John Armstrong and Dr. Jan Hamrin, "What are "Renewable Resources? (Chapter 1, The Renewable Energy Policy Manual ), Organization of American States.

[6] R. Walding, G. Rapkins and G. Rossiter, New Century Senior Physics: Knowledge, Processes and Reasoning”, Oxford University Press, 1999.

[7] D.S. Helman, "Catching lightning for alternative energy", Renewable Energy, Vol. 36, No. 5, Pp. 1311-1314, 2011.

[8] J.F. Vincent, O.A. Bogatyreva, N.R. Bogatyrev, A. Bowyer and A.K. Pahl, "Biomimetics: its practice and theory", Journal of The Royal Society Interface, Vol. 3, No. 9, Pp.471-482, 2006.

[9] J.F. Vincent, "Biomimetics-a review", Journal of Engineering in Medicine. Proceedings of the Institution of Mechanical Engineers, Pp. 919-939, 2009.

[10] AG DaimlerChrysler, “The History of Daimler-Benz AG”, Retrieved 27 January 2011. 